\title{
GABEL, Helmut, Widerstand und Kooperation. Studien zur politischen Kultur rheinischer und maasländischer Kleinterritorien (1648-1794)
}

\section{Christophe Duhamelle}

\section{OpenEdition}

\section{Journals}

Édition électronique

URL : http://journals.openedition.org/ifha/1474

DOI : $10.4000 /$ ifha. 1474

ISSN : 2198-8943

\section{Éditeur}

IFRA - Institut franco-allemand (sciences historiques et sociales)

\section{Référence électronique}

Christophe Duhamelle, «GABEL, Helmut, Widerstand und Kooperation. Studien zur politischen Kultur rheinischer und maasländischer Kleinterritorien (1648-1794) », Revue de I'IFHA [En ligne], Date de recension, mis en ligne le 01 janvier 1998, consulté le 22 septembre 2020. URL : http:// journals.openedition.org/ifha/1474 ; DOI : https://doi.org/10.4000/ifha.1474

Ce document a été généré automatiquement le 22 septembre 2020.

(CIFHA 


\title{
GABEL, Helmut, Widerstand und Kooperation. Studien zur politischen Kultur rheinischer und maasländischer Kleinterritorien (1648-1794)
}

\author{
Christophe Duhamelle
}

1 C'est d'abord à un voyage exotique dans les micro-principautés d'entre Rhin et Meuse que nous invite H.G.: la princesse-abbesse de Thorn règne sur 1,5 mille carré, mais a face à elle une Diète territoriale au complet; les comtes d'Aspremont-Linden cherchent à faire de leur comté de Reckheim (riche de trois paroisses) une sorte de forteresse de bout d'Empire, catholique et absolutiste; la principauté-abbaye de Kornelimünster, que l'on traverse en deux bonnes heures de marche, suscite une montagne stupéfiante de chicanes auprès des deux tribunaux d'Empire, la Chambre Impériale et le Conseil Aulique de Vienne.

2 Dans tous ces petits territoires en effet, les conflits entre princes et sujets sont nombreux. Contrairement aux idées reçues, les paysans du nord de l'Empire ne vivent pas dans une léthargie revendicative alourdie par la faiblesse des communautés villageoises, bien au contraire: H.G. montre le renforcement et l'élargissement social d'organisations communautaires qui, fortes d'une conception précise du bien commun, du nécessaire consentement des sujets, de la frontière entre les dépenses nécessaires et inutiles et du caractère licite de la résistance envers une politique princière qui s'écarte de la Billigkeit admise et met en péril les libertés paysannes, savent s'organiser pour entamer contre des princes sans grand pouvoir de coercition des actions de désobéissance et des recours juridiques complexes mais fréquents et efficaces.

Dans ces petits territoires aux structures judiciaires rudimentaires, les plaintes contre l'autorité parviennent en effet directement aux tribunaux d'Empire, dont l'influence s'avère ici déterminante, et dont les actes constituent les principales sources de l'étude. Telle sentence refuse à un petit prince le droit d'accroître ses impôts, telle autre interdit une corvée ponctuelle de charroi qui constitue une "nouveauté«, tandis que 
par le biais de commissions impériales le tribunal prend les choses en main quand la situation se détériore, ce qui est le cas à Kornelimünster (objet principal du livre) lorsque l'abbé B. G. von Gevertzhaen est assassiné en 1699, ou lorsqu'un de ses successeurs est déposé en 1768 pour troubles mentaux et va finir sa vie dans un couvent, stockant le sang de ses saignées en espérant qu'il en sorte des enfants...

4 C'est donc une culture politique de la tradition, de la participation, de la confrontation et du contrat (on relèvera l'importance du serment d'allégeance, dont le refus est souvent la première expression du conflit, et de l'accord entre prince et pays auquel on finit par parvenir en 1742 à Kerpen-Lommersum, en 1760 à Wickrath, en 1776 à Thorn, en 1714 et 1751 à Kornelimünster) qui s'exprime au sein de territoires encore pleinement inscrits dans une structure impériale à la fois pesante (la levée des impôts d'Empire et de Cercle initie fréquemment les conflits) et apaisante. Il faut donc tenter de dépasser le caractère un peu décourageant de cet ouvrage (récit d'une minutie impitoyable suivi d'une analyse conceptuelle parfois sidérale) et d'en saisir la richesse et la finesse, afin de retrouver à travers lui le courant historiographique qui continue à réhabiliter, au travers des réalités rurales, la diversité et l'originalité d'un Saint-Empire trop longtemps réduit à la gestation de quelques absolutismes. 